\title{
The Barriers and Enablers of the Educational Cloud: A Doctoral Student Perspective
}

\section{Mohammed Ali}

IMP Innovation, Strategy and Sustainability Alliance Manchester Business School, Innovation Management and Policy Division, Manchester Institute of Innovation Research IMP Innovation, Strategy and Sustainability, University of Manchester, Manchester, UK

Email: info@uksservices.com

How to cite this paper: Ali, M. (2019) The Barriers and Enablers of the Educational Cloud: A Doctoral Student Perspective. Open Journal of Business and Management, 7, 1-24.

https://doi.org/10.4236/ojbm.2019.71001

Received: August 3, 2018

Accepted: November 16, 2018

Published: November 19, 2018

Copyright (c) 2019 by author and Scientific Research Publishing Inc. This work is licensed under the Creative Commons Attribution International License (CC BY 4.0).

http://creativecommons.org/licenses/by/4.0/

\begin{abstract}
Background, Motivation and Objective: Cloud computing (CC) within UK HEIs is an emerging research phenomenon. When adopting new innovations, it is important to assess whether it will add value to the organisation. Contribution/Method: This exploratory empirical research is derived from the technology, organisation and environment model (TOE), which targeted higher education institutions (HEIs). A qualitative study, which explored the potential barriers and enablers of CC adoption by HEIs from a doctoral student perspective, was conducted, where 32 students at a University that had recently adopted the educational cloud situated in North-west England, were interviewed. Results/Discussion/Conclusion: The results showed that the most significant enablers of the educational cloud were cost efficiency, scalability, flexibility and mobility, and especially collaboration among students. Whereas the most significant barriers of the educational cloud were security and cultural resistance. In conclusion, the adoption rate of CC is increasing gradually in UK HEIs, which is mostly down to the cost efficient and collaborative nature of the educational cloud, but there is still the issue of privacy and trust in the educational cloud which impedes adoption.
\end{abstract}

\section{Keywords}

Cloud Computing, Higher Education Institutions, Barriers, Enablers, Students

\section{Introduction}

Cloud computing (CC) has become an important issue across industry. For example, the potential benefits of CC are now convincing various organisations and institutions to adopt the technology. It provides customers with computing as a service over a network via large-scale data centres or the cloud [1]. These 
have been investigated in a number of contexts ranging from large corporations [2] to educational institutions, such as schools, colleges and Universities [3] [4] [5] [6].

Alkhater et al. [7] came up with the explanation that benefits, such as reduced costs and the flexible nature of the cloud, are enough to convince organisations to migrate to the cloud. However, Kshetri [8] argues that many organisations are still unfamiliar with the cloud, and are likely to reject the technology due to the number of challenges and risks associated with the technology. It is therefore important for education institutions to consider the potential challenges and risks of migrating to the cloud before making their adoptive decision. In fact, potential investors attempt to reduce the severity of risk and abate uncertainty by carefully assessing the most critical business and system processes that could potentially benefit the most from the cloud [9]. Familiarity with innovation adoption factors helps organisations or institutions to adopt a more structured approach when analysing such factors.

However, assessing the technical factors is not enough at institutional level. It is important for innovation to be explored within both the institutional context and external environment. In view of Sultan [3], CC causes "IT commoditising". Owing to this argument, IT departments within institutions will anticipate resistance. The public cloud, for example, which is widely adopted by institutions, allows them to store data off-campus. The service provider is often outsourced to another country, and thus raises a number of potential risks associated with data privacy, among other legal aspects.

The UK, for example, is a developed country. Alharthi et al. [10] explain that $\mathrm{CC}$ is now allowing UK institutions to access highly complex infrastructures and advanced technology with very little investment needed. It also gives UK institutions an opportunity to access quality technologies with minimal expertise. Going forward, CC is expected to replace existing computing through the internal management of infrastructure and the development of large data centres. Relative advantage is heavily associated with cost efficiency and adhering to business requirements [3].

The existing literature has identified numerous definitions of CC. The most well-known and accepted definition comes from the National Institute of Standards and Technology (NIST) [11] as follows:

"Cloud computing is a model for enabling ubiquitous, convenient, on-demand network access to a shared pool of configurable computing resources (e.g., networks, servers, storage, applications, and services) that can be rapidly provisioned and released with minimal management effort or service provider interaction. This cloud model is composed of five essential characteristics, three service models, and four deployment models."-Mell and Grance [12]

It was surprising to find that there is limited research about the barriers and enablers of CC in the UK higher education context [10]. Therefore, this paper will contribute by understanding potential barriers and enablers of the educa- 
tional cloud in UK institutions from a doctoral student perspective. A doctoral student perspective was chosen because it is necessary to investigate the barriers and enablers of the educational cloud from a common user's point of view in University settings, as well as determining the role of CC in doctorial education; areas which have been under-researched. Doctoral students will likely use CC to support their studies or research, store vital course data and access their educational materials off-campus; or none of these depending on their personal views of the technology. Therefore, this will help to assess doctoral students' intentions for potentially using or not to use the educational cloud in their respected institution [13].

CC is a growing trend, and is considered a new area in the innovation and management information systems fields [14]. To the authors best knowledge based on the literature review, there is no previous papers that addresses the barriers (risk of non-adoption) and enablers (potential adoption) of the educational cloud (cloud technologies for higher education institutions), particularly from a doctoral student perspective (post-graduate $\mathrm{PhD}$ students), as well as the institutional, technological and environmental factors affecting CC in the UK context. Therefore, it would be interesting to determine whether there is a demand for the educational cloud among this specific student group, since other studies have found that the likes of college students [4] and under-graduate students [3] are in demand for an educational cloud.

\section{Literature Review}

This study adopts NIST's view of CC [12]. Since this publication, there are have been a number of academic studies which follow this same definition to support the literature review process [1] [2] [11] [15].

Here, an overview of CC, as well as a review of the barriers and enablers of CC in the higher education context is provided. Finally, a brief analysis of successful CC case studies in the higher education context is provided.

The CC model derives from several technologies, including the internet, web services, utility computing, grid computing and virtualisation. Low cost broadband and storage, as well as high speed wireless networks are all contributing factors toward the development of CC. Furthermore, CC is more than just outsourcing framework. Adapted from the work of Youssefand Alageel [16] and Eviwiekpaefe and Ajakaiye [17], five key characteristics of CC in the education context have been defined:

- Access to a wider network of computing resources: the ability to access network resources on numerous computing devices ranging from computers to smart phones;

- Self-Service on request: the ability to access cloud resources, such as email, applications, storage etc. anytime, anywhere;

- Pay-as-you-go service: paying only for the amount service used;

- Adaptability and flexibility: how far cloud resources are capable of adjusting 
to changing consumer demands;

- Resource centralisation: gathering and consuming shared resources over a network; service providers also use shared computing resources to offer customers cloud services.

The literature has also identified three key cloud service models and three key cloud deployment models Mell and Grance [12] used in the education context [3]:

\subsection{Service Models}

- Online cloud applications: this is a simplified term for Software as a Service (SaaS) where cloud vendors host applications, which customers can access over a network;

- Online operating systems: in other words, this is a Platform as a Service ( $\mathrm{PaaS})$, which enables customers to develop, run, and manage web applications without the need of establishing and maintaining the infrastructure associated with application development and execution, e.g. Linux hosting;

- Online tangible resources: this is essentially Infrastructure as a Service (IaaS) that offers visualised resources online or via a network [18] [19] [20].

Collectively, these service models can be referred to as an "aaSS" or as a service system. This seems more appropriate and simple to understand from a general user perspective compared to the technical jargon presented in the cloud literature. This would also sound more appealing to the average user of the cloud in the educational arena as they too may not be accustomed to the cloud jargon.

\subsection{Deployment Models}

- Open education cloud: in other words, public networks where users can access of pool of resources such as applications, databases and storage using web services or applications publicly or via the Internet. Public clouds are the most commonly used deployment models in educational institutions given they are the cheapest and most flexible option;

- Closed education cloud: in other words, private clouds that can be controlled and managed off-campus. Private clouds are considered the most secure cloud model given its extra level of security;

- Fusion education cloud: in other words, hybrid clouds where a combination of two or more clouds e.g. public and private;

- Community educational cloud: these are controlled and shared in the cloud environment by institutions, and caters for a particular community who have similar interests [12] [18].

Currently, there are a number of cloud services on the market, including email services, Google Apps, ERP systems and CRM Salesforce [21]. CC venders are now targeting higher education institutions (HEIs) [22] [23]. The next section provides a review of the existing literature pertaining to the barriers and enablers of adopting CC in HEIs. 


\subsection{CC in HE Context}

Several studies have explored the barriers and enablers of CC. However, this study will not cover all the key barriers and enablers, only those relevant to the HEI context. The following barriers and enablers have been deduced from the literature presented below.

\subsubsection{Enablers}

There are various benefits that can benefit the institution. The literature identifies some of the general benefits that can support CC in HEIs. Mell and Grance [12] explain that CC is a system that uses a network of services hosted remotely on the internet as a means of storing, managing and processing data, as opposed to a local machine or server [3]. In addition, a number of studies have identified numerous benefits of the cloud [64]:

Cost efficiency (relative advantage): the cost efficient nature of the cloud enables HEIs to minimise IT costs through spending less on computer hardware and software, reduce staffing costs by reducing the required personnel to maintain data, and save a significant amount of space and energy required to run their IT facilities [3] [12] [24]. Cost efficiency is regarded the most common enablers for CC adoption, particularly in the HEI context [3];

Collaboration: CC can improve collaboration between users and organisations. It allows them to implement tools, share applications and data, synchronise and work on documents simultaneously, and track colleagues and records to acquire real-time updates [25]. CC tools can therefore help both students and faculty to collaborate and communicate more freely online;

Scalability, flexibility and mobility: CC enables institutions to increase their business growth without the need to massively change existing IT systems, and the elasticity of the cloud enables institutions not only to implement solutions swiftly, but also increase computer capacity when required and remove them when not required so as to react faster to unanticipated growth in demand [25] [26] [27] [28] [29];

Improved business focus, performance and resource management: institutions can share applications and data on the cloud, thereby enabling staff and management to concentrate on business processes and initiatives in place of the IT infrastructure [30] [31] [32] [33].

Efficiency and agility: CC enables institutions to gain quick access to IT services they require without having to waste time and money on establishing their own IT infrastructure and capabilities [24];

Rapid deployments: CC can provide HEIs with a quicker and efficient means to develop services and applications, and thus deploying applications is a much faster process as this eliminates users worrying about issues over system compatibility and storage capacity [28] [34].

Greater availability/reliability: CC provides high-performance and scalable capabilities on-demand, while sustaining greater capital and operational expen- 
diture, and institutions that install applications on high-performance CC platforms are more than likely to achieve enhanced levels of business resiliency and continuity [29] [33] [35].

In the HE sector, one has to consider that the technology itself does not give them a competitive advantage given the rapid developments that occur within this environment. It is the users and the institution that provide this competitive advantage as there needs to be some level of interaction with the cloud system in order for it to perform the benefits that it sets out to achieve. Moreover, from a student perspective, CC can facilitate access to the online library, encourages knowledge and idea sharing among other students and staff, interact and learn with other students and teachers online anytime anywhere using various devices (collaboration), can encourage learning off-campus, online exams can be produced and allow students to take part in online projects [36] [37] [38].

In short, the success of the educational cloud depends on not just the technology itself, but the institution and users of the technology. Therefore, in order to get the most out of CC, HEIs must take into consideration all of the stakeholders who will be using the technology.

\subsubsection{Barriers}

Despite the various enablers of the educational cloud in HEIs, there are unfortunately barriers that affect the technology. Such challenges can be significant, complicated and costly, and require hard work, commitment, determination and encouragement from various stakeholders in order to overcome them. Since these barriers have a huge impact on all departments of HEIs, they can forever change their organisational culture and business processes [39] [40].

According to various authors, it is not often the technical barrier of the educational cloud that impact the institution's decision to adopt CC, but it is the organisational and personal barriers [39] [41] [42] [43] [44]. Despite the educational cloud bringing various opportunities, they can also be discouraging if the HEI and their stakeholders are not fully aware of the benefits and challenges [45]. The most significant challenges of CC include:

Security: in CC environments, HEIs can easily lose control over data, while simultaneously maintaining the availability, integrity and confidentiality of information [10] [29] [46] [64]. CC also generates new vulnerabilities and threats, which further contributes to the magnitude of risks and challenges facing traditional IT environments. Potential attackers can access private data and applications on the cloud network, and thus presents a host of privacy concerns in cloud environments where sensitive information or data can be disclosed to a third party [3]. Users could therefore lose trust in the cloud system [47];

IT maturity: given the unproven nature of the cloud as it is a relatively new technology, particularly in HEIs, can lead to future uncertainty of the technology, particularly in terms of potential threats and vulnerabilities, leading to institutions rejecting the technology [48];

Cultural resistance: this involves HEIs and its users facing organisational 
inertia, since migrating from the traditional system to a new cloud system may unexpectedly change their roles and responsibilities, as well as the ways about performing their job [49] [50] [51];

Migration issues: migrating to the cloud can put HEIs' data at risk. Vendor lock-in can restrictaccess to the systems or data hosted by the cloud provider [52], and in the worst case a potential loss of data;

Compliance: institutions are liable for ensuring data security and integrity, even when being held by cloud providers, and thus need to comply with security standards irrespective of where the applications or data are located [26] [34].

In particular, students would most likely be affected by the security aspects of the cloud as they would now have to place their trust in a system they are unaccustomed to, not to mention the cultural resistance of a newly implemented system. CC is a relatively new technology, and will alter the traditional daily operations [3]. Therefore, student perceptions could in fact significantly impact on HEIs decision to consider the educational cloud.

In short, the limited use of the educational cloud in HEIs is often down to the barriers that reflect technological acceptance [10]. If HEIs are unaware of the benefits and opportunities, this would not only lead to the rejection of CC in the education sector, but to the lack of maturity of the technology in this sector, and thus HEIs will miss out on what CC can bring to them going forward [23].

\subsection{Successful CC Cases in HEIs}

There are a few known cases from around the world regarding the successful adoption of CC in HEIs. This paper has deduced three of the most successful cases from Greenwich University [53], MBA Group Projects [54] and the University of Westminster [3].

\subsubsection{Case 1: Greenwich University}

In the case of Greenwich University, a service model called "Education as a Service" (EaaS) was introduced. It helped to transform the way educational services and operations are delivered to students [53]. It was found that the model not only supported the university to accept and implement CC, but demonstrated a number of benefits, such as simple consolidation of existing resources and services, and improving students' learning satisfaction, and teachers' instruction, students were keen to learn and undertake coursework, thereby further improving students' learning experience.

\subsubsection{Case 2: MBA Group Projects}

Another successful case was found in the study of Tan and Kim [54]. A case of Google Docs in MBA group projects was conducted. The case study focused on determining whether or not Google Docs was a viable alternative to their existing Microsoft Office package. A mixed methodology (qualitative and quantitative) was used to gather data via both questionnaires and interviews. Both sets of results showed that MBA students held relatively positive perceptions about the use of Google Docs based on their IT skills and experience of using the software. 
It was concluded that Google Docs is a cheaper and more viable solution as the majority of students found the system to be useful and as effective as their existing MS Office package, which comes at a significant cost.

\subsubsection{Case 3: University of Westminster}

Sultan [3] also conducted a case study to highlight the potential benefits that could influence the adoption of CC. The case study was based in the UK and was conducted at the University of Westminster. It was revealed that the institution's interest to adopt was down to their current email system being out of date, thus a CC Gmail system was proposed. The University looked to Google Apps for their solution. This platform aimed to provide free on-campus email to students and staff, in addition to productivity applications, such as word processing, spreadsheets and presentations with collaborative support (ideal for group-work assignments). The results showed that students had a good experience of using the new solution, and there were additional economic benefits which influenced the University's decision to adopt. There were minimal costs of using the Gmail service, and it was estimated to provide equivalent storage to systems that would have potentially cost the University $£ 1 \mathrm{~m}$ to install, maintain, upgrade, and to cover staffing costs, storage, licences and servers etc.

However, the university did not go ahead with adopting Google Apps as a long-term solution, given the security and privacy issues surrounding the transfer from the traditional email system to the new Gmail system. Not only that, students began to neglect the new system and opted to use their personal email addresses instead. It was concluded that despite the Gmail system did encourage the likes of collaborative learning and the ability to share resources efficiently at a minimal cost, the university did not go ahead with the adoption process. This was due to the legal implications of transferring all of their existing data to a new system they were unfamiliar with, and were highly sceptical about trusting their data with a third party.

\subsection{Summary}

In short, the literature has yet to determine the full extent of the above barriers and drivers from a doctoral student perspective, and in terms of the specific technical, organisational and environmental aspects that influence these barriers and drivers. There also needs to be more success cases like the ones at Greenwich University, University of Westminster and the MBA project, but due to the unfamiliarity of CC among HEIs, as well as the challenges that could potentially hinder their IS development, is still a key issue within the HE sector. Therefore, this paper uses the TOE model to pin point the specific barriers and drivers that relate to the educational cloud from a doctoral student perspective using the already identified drivers and barriers from the existing literature.

\section{Research Model}

The Technology, Organisation and Environment (TOE) framework was used as 
the chosen approach for this research. Haag and Eckhardt [11] state that the model was developed by Tornatzky and Fleischer in 1990 for the purpose of classifying a range of factors that can support or hinder the adoption of technological innovations in various contexts, including institutions. These factors in the context of this paper refer to the barriers and enablers of CC adoption in HEIs. In addition, TOE is a more effective model than the likes of Diffusion of Innovation (DOI) and Technology Acceptance (TAM) in that considers not only the technological and organisational factors, but also environmental factors [55].

TOE has also been used in the CC contexts [11]. Prior to the use of the model in CC, it was used in similar fields, like Internet, e-business and open system use. TOE has even been used to test the educational cloud in HEIs in developed countries [3]. The literature has found that factors ranging from cost efficiency to security issues massively contribute to the variance of CC adoption in HEIs.

The identified barriers and enablers of CC adoption in HEIs from the literature are covered from not only at institutional level, but also at personal level (doctoral student perspective), and were categorised accordingly (see Figure 1) [6] [55] [56] [57]. Table 1 and Table 2 show the components of the TOE model coupled with the identified barriers and enablers from the literature, all of which are appropriately categorised (see Figure 1 for adapted model).

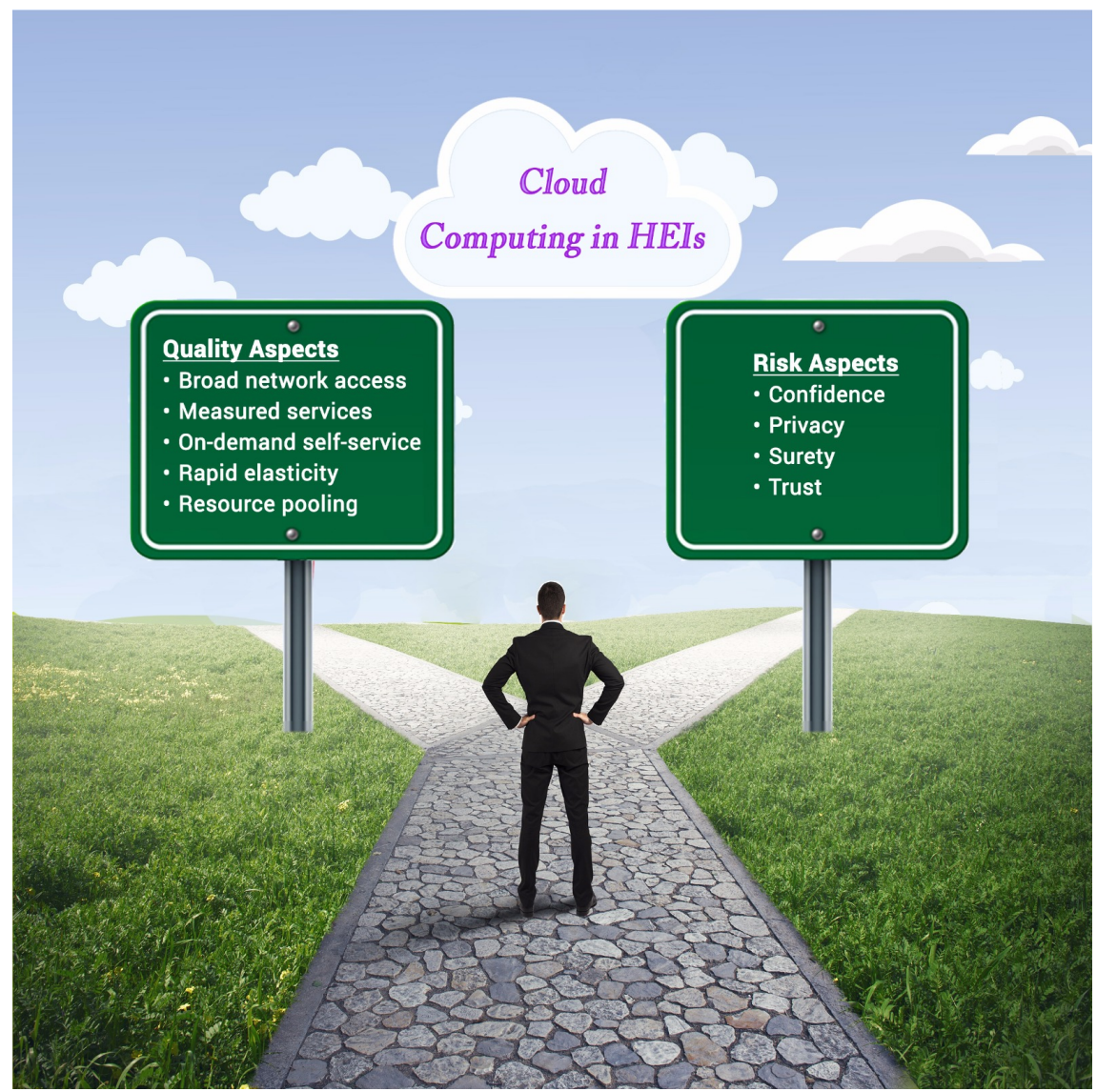

Figure 1. Research model. 
Table 1. TOE model components (Enablers) [6] [55] [56] [57].

\begin{tabular}{|c|c|c|}
\hline Component & Definition & TOE aspect \\
\hline Relative advantage & $\begin{array}{l}\text { The degree to which cloud computing can provide } \\
\text { a greater benefit to HEIs }\end{array}$ & Technology \\
\hline Cost efficiency & $\begin{array}{l}\text { Minimising IT costs through spending less on } \\
\text { computer hardware and software, reduce staffing } \\
\text { costs by reducing the required personnel to } \\
\text { maintain data, and save a significant amount of } \\
\text { space and energy required to run their IT facilities }\end{array}$ & $\begin{array}{l}\text { Organisation } \\
\text { Environment }\end{array}$ \\
\hline Compatibility & The degree to which CC fits HEIs needs. & Technology \\
\hline Collaboration & $\begin{array}{l}\text { The degree of which institutions and their } \\
\text { students can implement tools, share } \mathrm{x} \text { applications } \\
\text { and data, synchronise and work on documents } \\
\text { simultaneously, and track colleagues and records } \\
\text { to acquire real-time updates. In other words, } \\
\text { students and faculty can collaborate (work } \\
\text { together) and communicate more freely online. }\end{array}$ & Organisation \\
\hline $\begin{array}{l}\text { Scalability, flexibility } \\
\text { and mobility }\end{array}$ & $\begin{array}{l}\text { Institutions can increase their business growth } \\
\text { without the need to massively change existing IT } \\
\text { systems, and the elasticity of the cloud enables } \\
\text { institutions not only to implement solutions } \\
\text { swiftly, but also increase computer capacity when } \\
\text { required and remove them when not required so } \\
\text { as to react faster to unanticipated growth in } \\
\text { demand. }\end{array}$ & $\begin{array}{c}\text { Technology } \\
\text { Environmental }\end{array}$ \\
\hline $\begin{array}{l}\text { Improved business } \\
\text { focus, performance and } \\
\text { resource management: } \\
\text { infrastructure }\end{array}$ & $\begin{array}{l}\text { Institutions can share applications and data on the } \\
\text { cloud, thereby enabling staff and management to } \\
\text { concentrate on business processes and initiatives in } \\
\text { place of the IT. }\end{array}$ & Organisation \\
\hline Efficiency and agility & $\begin{array}{l}\text { The degree of which institutions can gain quick } \\
\text { access to IT services they require without having } \\
\text { to waste time and money on establishing their } \\
\text { own IT infrastructure and capabilities. }\end{array}$ & Organisation \\
\hline Rapid deployments & $\begin{array}{l}\text { HEIs can be provided a quicker and efficient means } \\
\text { to develop services and applications, and thus } \\
\text { deploying applications is a much faster process as } \\
\text { this eliminates users worrying about issues over }\end{array}$ & Technology \\
\hline $\begin{array}{c}\text { Greater } \\
\text { availability/reliability }\end{array}$ & $\begin{array}{l}\text { Provision of high-performance and scalable } \\
\text { capabilities on-demand, while sustaining greater } \\
\text { capital and operational expenditure, and institutions } \\
\text { that install applications on high-performance CC }\end{array}$ & Technology \\
\hline CC adoption & The degree of which HEIs plan to & - \\
\hline HEIs & Higher education intuitions and their role in CC & - \\
\hline HEI size & Number of students in the HEI & - \\
\hline Students & Key users of the cloud in HEIs. & - \\
\hline
\end{tabular}

\section{Research Model}

Figure 1 represents the research model and the proposed constructs. The benefits 
Table 2. TOE model components (Barriers) [6] [55] [56] [57].

\begin{tabular}{|c|c|c|}
\hline Component & Definition & TOE aspect \\
\hline Complexity & $\begin{array}{l}\text { The degree to which HEIs find difficulty to understand } \\
\text { or use the cloud. }\end{array}$ & Technology \\
\hline Security & $\begin{array}{l}\text { The degree of which HEIs can easily lose control over } \\
\text { data, while simultaneously maintaining the availability, } \\
\text { integrity, privacy and confidentiality of information. It } \\
\text { generates new vulnerabilities and threats, contributing to } \\
\text { further risks and challenges facing traditional IT } \\
\text { environments, such as potential attackers who can access } \\
\text { private data and applications on the cloud. }\end{array}$ & Technology \\
\hline IT maturity & $\begin{array}{l}\text { Given the unproven nature of the cloud as it is a } \\
\text { relatively new technology, particularly in HEIs, can lead } \\
\text { to future uncertainty of the technology, particularly in } \\
\text { terms of potential threats and vulnerabilities, leading to } \\
\text { institutions rejecting the technology }\end{array}$ & Environment \\
\hline Cultural resistance & $\begin{array}{l}\text { The degree of which HEIs and its students face } \\
\text { organisational inertia, since migrating from the } \\
\text { traditional system to a new cloud system may } \\
\text { unexpectedly change their roles and responsibilities, as } \\
\text { well as the ways of going about their daily activities. }\end{array}$ & Organisation \\
\hline Migration issues & $\begin{array}{l}\text { Migrating to the cloud can put HEIs' data at risk. } \\
\text { Vendor lock-in can restrict access to the systems or data } \\
\text { hosted by the cloud provider, or in the worst case, a } \\
\text { potential loss of data. }\end{array}$ & Technology \\
\hline Compliance & $\begin{array}{l}\text { The degree of which institutions are liable for ensuring } \\
\text { data security and integrity, even when being held by } \\
\text { cloud providers, and thus need to comply with security } \\
\text { standards irrespective of where the applications or data } \\
\text { are located }\end{array}$ & Environment \\
\hline CC adoption & The degree of which HEIs plan to adopt CC. & - \\
\hline HEIs & $\begin{array}{l}\text { Higher education intuitions and their role in CC } \\
\text { adoption. }\end{array}$ & - \\
\hline HEI size & Number of students in the HEI & - \\
\hline Students & Key users of the cloud in HEIs. & - \\
\hline
\end{tabular}

and enablers (aspects) in each of the three areas were identified from the existing literature [3] [10] [24]-[30] [32] [33] [46] [47] [48] [50] [52] [58] [59] [64].

Here, the barriers and enablers identified in the literature were categorised according to the TOE framework. It was deduced that issues such as relative advantage, compatibility, complexity, scalability, flexibility, mobility, greater availability, security and migration issues impact the technological aspects impacting cloud adoption in HEIs. Cost efficiency, collaboration, improved business focus, efficiency, agility and cultural resistance were found to impact the organisational aspects of cloud adoption in HEIs. Lastly, compliance, stability, flexibility, mobility and innovation maturity impact the environmental aspect of cloud adoption in HIEs. 


\section{Methodology}

This research is an exploratory qualitative based study. Semi-structured interviews were used to gather primary data and to meet the aim of this paper. Open-ended questions were asked to participants in order to capture qualitative data.

\subsection{Population and Sample}

The target population is UK universities that have some experience of using a cloud solution that has influenced doctoral students' learning experience. Based on the previous case studies presented in the literature review, some UK Universities that have already adopted and used CC in the past, Greenwich University and the University of Westminster. However, these two Universities are unsuitable as these studies have already determined the impact of CC. After doing some extensive research, there was another University based in the North-West of England discovered to have recently adopted the cloud, and no previous case studies have been conducted. Therefore, this research interviewed doctoral students from this particular University based in North-West England. Since there are limited case studies in the UK context, the previous UK case studies were compared to the results discovered in this paper, in order to determine the effectiveness of CC adoption in UK HEIs from a doctoral student perspective. Moreover, a sample of 20 doctoral students was interviewed. With respect to ethics, both the University's and participant's names were kept anonymous and were referred to as alternative pseudonyms e.g. student A.

\subsection{Data Collection}

HEIs in the UK represent the research population. The sample of the research was also drawn. Ross [60] states that HEIs are considered a potential customer or consumer of cloud services as opposed to an actual vendor. The data collection tool was semi-structured interviews. The student interviews were conducted in a private room on-campus and were obtained through doctoral students volunteering to take part via word of mouth from some of their lecturers. A total of 32 interviews were conducted (out of an initial sample of 40), thus yielding an $80 \%$ response rate. Four interviewees failed to turn up for the interview. In addition, 26 positive responses and 6 negative responses were given. Therefore, a total of 32 valid responses were analysed.

\subsection{Data Analysis}

Thematic analysis was used to analyse the research data. Following verbatim transcription, the data was analysed. Descriptive accounts of the research data were presented and the most significant findings were deduced. N-Vivo was the tool used to analyse the research data, namely the open-ended interview questions [61] [62]. 


\section{Findings and Discussion}

The findings below reflect the key aspects of the TOE model in relation to the most significant barriers and enablers of CC in HEIs from a doctoral student perspective. Table 3 provides an overview of each respected student who took part in this research.

\subsection{Enablers}

It was discovered that cost efficiency, collaboration and scalability, flexibility and mobility were among the most significant enablers of CC among students.

Table 3. Research participants.

\begin{tabular}{|c|c|c|c|}
\hline Student & Department & Year & Age \\
\hline A & Business school & 1 & 30 \\
\hline B & Law & 3 & 45 \\
\hline $\mathrm{C}$ & IT & 2 & 34 \\
\hline $\mathrm{D}$ & Business school & 1 & 25 \\
\hline E & Law & 3 & 42 \\
\hline F & IT & 2 & 33 \\
\hline G & IT & 2 & 36 \\
\hline $\mathrm{H}$ & Business school & 1 & 41 \\
\hline I & Law & 3 & 27 \\
\hline $\mathrm{J}$ & IT & 2 & 29 \\
\hline $\mathrm{K}$ & Business school & 1 & 40 \\
\hline $\mathrm{L}$ & IT & 1 & 31 \\
\hline $\mathbf{M}$ & Law & 2 & 24 \\
\hline $\mathrm{N}$ & Business school & 1 & 34 \\
\hline $\mathrm{O}$ & IT & 3 & 24 \\
\hline $\mathbf{P}$ & Law & 2 & 33 \\
\hline Q & Business school & 1 & 32 \\
\hline $\mathbf{R}$ & Business school & 2 & 31 \\
\hline$s$ & IT & 3 & 25 \\
\hline $\mathrm{T}$ & IT & 1 & 31 \\
\hline $\mathrm{U}$ & Law & 3 & 27 \\
\hline $\mathrm{V}$ & Law & 2 & 29 \\
\hline $\mathrm{W}$ & IT & 2 & 30 \\
\hline $\mathrm{X}$ & Business school & 1 & 21 \\
\hline $\mathrm{Y}$ & Business school & 1 & 24 \\
\hline $\mathrm{Z}$ & Business school & 1 & 41 \\
\hline $\mathrm{A} 1$ & IT & 3 & 32 \\
\hline
\end{tabular}


Relative advantage: When institutions see that a particular innovation can potentially offer a relative advantage, it would more likely suggest that they are willing to adopt that innovation [63]. In order to achieve this, however, institutions and their students must have become accustomed to the relative advantages of CC. In the context of this research, relative advantage leaned more towards the cost efficiency benefit of cloud technology.

Cost efficiency: It was quite clear that all 32 students (students A-F1) interviewed had a firm grasp of the CC innovation adopted at their institution, and demonstrated a number of cost benefits. Students A, E, M and P indicated that CC has significantly reduced the cost of external storage. Student A mentioned: "the cloud has saved me money, since the alternative would have been to purchase an external storage device, which costs significantly more." Similarly, student $\mathrm{E}$ indicated: "the cost of storage space, in addition to having a free 10GB one-drive storage and a Google Apps is much less than the cost of an external hard-drive." This supports views of various researchers as the cost efficient nature of the cloud helps HEIs to minimise IT costs through spending less on maintain and upgrading outdated IT facilities [3] [12] [13] [24], thus leading to a better learning experience.

Finally, Student $\mathrm{M}$ further added: "the cloud has significantly reduced printing costs as I can simply show the work to my supervisor on the cloud without having to print everything." This demonstrates that students not only save money, but also help the environment by wasting less paper.

Compatibility: it was observed that the cloud did meet the University's needs. This was apparent from the responses pertaining to the collaborative nature of the cloud, as well as all 32 respondents (students A-M) agreeing that the cloud supports their daily activities [33].

Collaboration: all 32 students (A-F1) provided an interesting view of the collaborative cloud. They all shared the same belief that the collaborative cloud facilitates group learning and communication.

Student A indicated: "the cloud provides a simple, but effective means of sharing information and collaborating with fellow students. I can use the cloud to communicate more easily and for group work". Student F mentioned: "the cloud application is highly structured. It also allows me to manage my assignments via project and each project comes with its own task notes, files and conversations. It also allows me to share files with individuals who are affiliated with the project team." Student A1 indicated: "the collaborative nature of the cloud encourages teamwork and facilitates communication. The collaborative cloud also facilitates file sharing in a more organised fashion. With regards to my course, sharing information was a smooth process and when engaging in group work with fellow students, much work was completed without having to meet up personally." Student B mentioned: "document sharing and group chat were very useful. Each group member completes their group task of the project and then uploads their work to the shared cloud, which all of my group members can access 
from any location, at any time, and from any device. From there, we can observe the group's progress and the uploaded work from each member. A cloud application called team box, which enabled me to communicate or chat to my team members was very useful so there was no need to send emails to each other. Chat helped the group to get their points and queries across much clearer." Student G indicated: "the chat feature allows for better communication between group members in real-time. The note feature allows for sharing opinions and discusses them among group members". Student C even mentioned: "I am able to engage in my group work more effectively via the cloud's collaborative features, like the notes and discussion features, and makes sharing assignment and project materials with fellow group members much easier. I can engage in various discussions with fellow groups without having to meet face-to-face."

Willcocks et al. [25] affirms that CC can improve collaboration between users and organisations, as well as allowing institutions to implement tools, share applications and data, synchronise and work on documents simultaneously, and track colleagues and records to acquire real-time updates. This confirms that CC tools can facilitate students' ability to collaborate and communicate more freely online.

Scalability, flexibility and mobility: eleven students (students A-I, K and $\mathrm{L}-\mathrm{U}$ ) raised the issue of scalability, flexibility and mobility, and had mixed responses about the issue.

Student B mentioned: "the ability to access various applications via any web browser and on any of my smart devices is highly effective." A further eight students echoed similar responses (students C-I), such as: "using the applications anytime anywhere" (student C), "each activity on the cloud can be done via this effective cloud application every time everywhere" (student $\mathrm{K}$ and L-U), and "it is available at any time" (student D). Student $\mathrm{E}$ even stated: "my colleagues and I can even update our opinion at any time via this application".

Students J, M, P and A1-F1 contended the idea that the elastic nature of the cloud reflects its flexibility in that the University was able to implement its CC solution quickly without affecting other surrounding systems. Student J, in particular, indicated: "accessing the files in any computer or device is very easy and no portable external storage device, such as a pen drive is required".

A number of studies agree that the elastic and highly associable nature of the cloud enables institutions implement solutions swiftly, and increase computer capacity when needed [25] [26] [27] [28] [29].

\subsection{Barriers}

It was discovered that security and cultural resistance were among the most significant barriers of CC among students.

Complexity: with regards to complexity, all 32 students (students A-F1) agreed that $\mathrm{CC}$ was not difficult to use, but rather the existing problems that may hinder their CC experience, such as security and privacy flaws. 
Security: all 32 participants (students A-F1) provided some interesting insights about security in the cloud, most of which centred on privacy and data protection related issues.

Student A indicated: "the cloud is an effective tool that supports collaborative learning, but I feel that these systems are at huge risk." "The lack of privacy and encryption techniques that can prevent sensitive information, such as usernames, passwords, grades and course materials from being disclosed from the masses presents a host of security concerns." (Student M). Student L indicated: "I feel that the cloud provides Universities less power over controlling data on the cloud, which can present a host of risks to the University's IT infrastructure." Student D mentioned: "the current issue regarding cloud security derives from the SLA. Service level agreements must be stricter so as to improve the integrity and privacy of data, and to clamp down on potential risks the cloud could be exposed to."

Alharthi et al. [10] affirms that HEIs can lose control of data, while simultaneously maintaining the availability, integrity and confidentiality of information. Potential attackers can access private data and applications on the cloud, thereby presenting a host of privacy concerns in cloud environments where sensitive information or data can be disclosed to a third party [3], and thus students lose trust in the cloud system [29] [33] [46] [47].

Cultural resistance: the results do not entirely indicate cultural resistance, but rather a rejection of some cloud services as they were deemed inappropriate by students (students A-M). Students A, C, E and G-U agreed that the Gmail system was a redundant and pointless system as they could use their personal emails, which were as effective. Student A indicated: "I do not see the point of using a free cloud emailing service I am already using for my personal account. This cloud service adds no value to the University's IT infrastructure. I would rather use my personal email for my University activities." Student $C$ indicated: "Gmail is good, but there is no point of making another account, since I already have an account with the same email provider. Why can't I just use my personal email?" This indicates rejection not down to the cultural shift in the University's IT infrastructure, but rather a complete rejection of a system they deemed inappropriate.

However, students B, D, F and V-F1 argued that the Gmail system had some purpose. Student B, in particular, indicated: "Gmail is great. I use another email provider for my personal email, and making a Gmail account had provided me with a host of Google related applications to support my learning."

It can be deduced that those students who already had a Gmail account found Gmail inappropriate, while those who had just set up an account found the system useful. Similarly, there was a case at University of Westminster where they shifted their existing emailing system to the cloud-based Gmail system was deemed a redundant technology as many students used their personal emails, and thus had no need of using the Gmail platform. Although this was a cost efficient 
solution as it would save the University almost $£ 1 \mathrm{~m}$ in infrastructure costs, students still neglected the system and used their personal accounts instead [3].

\subsection{Reflection}

On reflection, CC was regarded by doctoral students as a simple and highly effective solution to support their learning experience, particularly with regards to collaboration, namely sharing ideas and work and communicating over the cloud without having to meet in person. Therefore, collaboration was regarded the most significant enabler of cloud technology use in HEIs. Despite this, students did voice their concerns about the security aspects of the educational cloud, citing that the cloud could potentially disclose personal data and become vulnerable to attackers, thus calling for better security measures to be imposed on the educational cloud. Table 4 deduces the most significant findings in this paper in comparison to the existing literature.

Table 4. Summary of findings.

\begin{tabular}{|c|c|c|}
\hline Component & Definition & TOE aspect \\
\hline Cost-efficiency & $\begin{array}{l}\text { - Spending less on computer } \\
\text { hardware and software, } \\
\text { - Reduce staffing costs } \\
\text { - Saving on space and energy } \\
\text { required to run IT facilities }\end{array}$ & $\begin{array}{l}\text { - Significantly reduced the cost of external } \\
\text { storage } \\
\text { - Free and cheaper external storage services } \\
\text { - Eliminates online storage costs } \\
\text { - Cost linked with green IT: eliminates } \\
\text { printing costs } \\
\text { - Demonstrates not only cost savings, but } \\
\text { environmental benefits environment by } \\
\text { wasting less paper }\end{array}$ \\
\hline Collaboration & $\begin{array}{l}\text { - Increases collaboration } \\
\text { between users and } \\
\text { organisations } \\
\text { - Implement tools } \\
\text { - Share applications and data } \\
\text { - Synchronise and work on } \\
\text { documents simultaneously } \\
\text { - Track colleagues and records } \\
\text { to acquire real-time updates }\end{array}$ & $\begin{array}{l}\text { - Facilitates group learning and } \\
\text { communication } \\
\text { - Provides simple and effective means of } \\
\text { sharing information } \\
\text { - Communicate easily with professors and } \\
\text { fellow students } \\
\text { - Promotes the management of } \\
\text { assignments and research projects: each } \\
\text { project comes with its own task notes, } \\
\text { files and conversations. } \\
\text { - Promotes file sharing with the project } \\
\text { team } \\
\text { - Smooth data sharing process when } \\
\text { engaging in group work with fellow } \\
\text { students } \\
\text { - Work can be done without having to } \\
\text { meet up personally } \\
\text { - Data and work progress monitoring: } \\
\text { other group member's progress and } \\
\text { uploaded work can be observed } \\
\text { helped to get points and queries across } \\
\text { much clearer in real-time }\end{array}$ \\
\hline
\end{tabular}




\begin{tabular}{|c|c|c|}
\hline $\begin{array}{c}\text { Flexibility, } \\
\text { scalability and } \\
\text { mobility }\end{array}$ & $\begin{array}{l}\text { - Increase business growth } \\
\text { without changing existing IT } \\
\text { systems } \\
\text { - Elasticity of the cloud allows } \\
\text { to implement solutions swiftly } \\
\text { and increase computer } \\
\text { capacity }\end{array}$ & $\begin{array}{l}\text { - Easy access to various applications via any } \\
\text { web browser on any smart device or PC } \\
\text { - Anytime anywhere access } \\
\text { - Easy access to files on any computer or } \\
\text { device } \\
\text { - Requires no portable external storage } \\
\text { device, such as a pen drive }\end{array}$ \\
\hline Security & $\begin{array}{l}\text { - Loss of control over data } \\
\text { - Generates new vulnerabilities } \\
\text { and threats } \\
\text { - Risk of attackers accessing } \\
\text { private data and applications } \\
\text { on the cloud; this presents a } \\
\text { host of privacy concerns where } \\
\text { sensitive information or data } \\
\text { can be disclosed to a third } \\
\text { party } \\
\text { - Lack of trust }\end{array}$ & $\begin{array}{l}\text { - Privacy and encryption techniques } \\
\text { presents a host of security concerns, such } \\
\text { as data disclosure and hacking } \\
\text { - No control over data } \\
\text { - Security derives from the SLA: The } \\
\text { e Service level agreements must be stricter } \\
\text { to improve the integrity and privacy of } \\
\text { data, and to clamp down on potential } \\
\text { risks the cloud could be exposed to }\end{array}$ \\
\hline $\begin{array}{l}\text { Cultural } \\
\text { resistance }\end{array}$ & $\begin{array}{l}\text { Organisational inertia: } \\
\text { migrating from the traditional } \\
\text { system to a new cloud system } \\
\text { can change roles and } \\
\text { responsibilities }\end{array}$ & $\begin{array}{l}\text { - Did not entirely indicate cultural } \\
\text { resistance, but rather a rejection of some } \\
\text { cloud services that were deemed } \\
\text { inappropriate } \\
\text { - Gmail system was a redundant and } \\
\text { pointless system, since personal emails } \\
\text { were a better alternative }\end{array}$ \\
\hline
\end{tabular}

\section{Contribution}

On a theoretical level, this research may provide potential adopters (Universities) of CC an insight about the most significant factors affecting CC adoption, especially given that the results reflect the barriers and enablers of CC from a doctoral student perspective. The enablers that support CC adoption among doctoral students were cost efficiency, the scale, flexible and mobile nature of the cloud and especially collaboration. However, doctoral students expressed security, compliance and technological resistance as barriers that impede the effective use of the cloud. For those reasons, much focus should be placed on promoting the benefits of the educational cloud to increase the level of adoption, but to consider the risks to avoid any biases toward the technology. This was supported by the classification of the most significant barriers and enablers of the educational cloud from a doctoral student perspective to influence potential HEIs in the UK decision to adopt the technology. Moreover, this research helped to fill the literature gap pertaining the significant barriers and enablers of the educational cloud from a doctoral student perspective.

On a methodological level, this research provided in-depth qualitative research, including a sound methodology for promoting CC adoption in UK HEIs. Face-to-face semi-structured interviews were used to gather appropriate data about the potential barriers and enablers of the educational cloud in UK HEIs 
from a doctoral student perspective. Interviewing doctoral students of a known University to have adopted some kind of cloud solution situated in North-west England UK HEIs made this achievable. The interviews helped to reflect on the most significant barriers and enablers of the educational cloud identified by the doctoral students interviewed.

On a practical level, the proposed model (adapted from the TOE model) in Section 3 helped to deduce the most significant barriers and enablers of the educational cloud in the HEI context from the existing literature. This provided a roadmap to test these deduced barriers and enablers from a doctoral student perspective to see which ones impacted them the most. It was deduced that the technical factors reflected the security, scalability, flexibility and mobility and cost efficient aspects of the educational cloud, the organisational factors reflected collaborative nature of the cloud and cultural resistance, and the environmental factors reflected compliance of the educational cloud.

In short, this research may also help decision makers in HEIs to make their adoptive decisions when considering the educational cloud, and serves as a benchmark for IT decision makers in UK HEIs, namely universities.

\section{Conclusions}

This study targeted UK HEIs and their respected doctoral students. Although the response rate was rather low, the external validity of this study was relatively high. It is vital that HEIs invest in future technologies that support their core business. It was found that $\mathrm{CC}$ has the potential to succeed in the educational arena going forward. It is important that curriculums associated with IS disciplines are updated to include CC and prepare HEIs for the new trend. It would be great to see the promotion of the educational cloud in the likes of workshops and conferences to convince potential adopters to invest in the technology to maximise return on investment going forward. Unbiased research papers on cloud adoption in the educational arena are valued resources for decision makers.

The most notable barrier of the educational cloud was security, namely the degree of privacy and trust, which can impede adoption. There appears to be an element of distrust regarding the storage of data assets, such as doctoral students' work and records. Despite this, the most notable enabler of adopting the educational cloud among doctoral students was the technology's ability to deliver effective collaboration, thereby improving doctoral students' overall learning experience. Moreover, it is important that cloud service providers are more involved in establishing more trust in cloud services and offer a better levels of service quality and security so as to promote the adoption of not only CC in general, but the adoption of the educational cloud in HEIs as well.

Since this was a mono study that only used one data collection tool (interviews), validating the data was rather restricted, and thus conducting a mixed study comprising of both quantitate and qualitative methods would be ideal to strengthen the validity the research findings (interviews and surveys perhaps). It 
would be recommended to conduct this mixed study about the risk mitigation measures taken by CC adopters in an attempt to address the security issues, namely data privacy issues identified in this research so as to provide a much stronger case for adopting the educational cloud in UK Universities. This will help to address the data privacy aspects in the SLA or coming to the realisation that CC is more secure than what is alleged prior to adoption.

This study can be repeated in future studies to explore the long-term migration of the educational cloud for the target population and contributing factors. This study can also be conducted in other countries (preferably developing as this study was conducted in a developed country) as a means to compare the most significant factors with the ones identified in this study. Moreover, including a construct about the reliable nature of the educational cloud would also be recommended as the majority of doctoral students voiced their concerns about the security aspects of the technology, despite their notable appraisals of it.

\section{Conflicts of Interest}

The authors declare no conflicts of interest regarding the publication of this paper.

\section{References}

[1] Abdollahzadegan, A., et al. (2013) The Organizational Critical Success Factors for Adopting Cloud Computing in SMEs. Journal of Information Systems Research and Innovation (JISRI), 4, 67-74.

[2] Gangwar, H., Date, H. and Ramaswamy, R. (2015) Understanding Determinants of Cloud Computing Adoption Using an Integrated TAM-TOE Model. Journal of Enterprise Information Management, 28, 107-130. https://doi.org/10.1108/JEIM-08-2013-0065

[3] Sultan, N. (2010) Cloud Computing for Education: A New Dawn? International Journal of Information Management, 30, 109-116. https://doi.org/10.1016/j.ijinfomgt.2009.09.004

[4] Behrend, T.S., et al. (2011) Cloud Computing Adoption and Usage in Community Colleges. Behaviour \& Information Technology, 30, 231-240. https://doi.org/10.1080/0144929X.2010.489118

[5] Wu, W.-W., Lan, L.W. and Lee, Y.-T. (2013) Factors Hindering Acceptance of Using Cloud Services in University: A Case Study. The Electronic Library, 31, 84-98. https://doi.org/10.1108/02640471311299155

[6] Scholten, J. (2017) The Determinants of Cloud Computing Adoption in The Netherlands: A TOE-Perspective. University of Twente, Enschede.

[7] Alkhater, N., Wills, G. and Walters, R. (2014) Factors Influencing an Organisation's Intention to Adopt Cloud Computing in Saudi Arabia. IEEE 6th International Conference on Cloud Computing Technology and Science (CloudCom), IEEE.

[8] Kshetri, N. (2010) Cloud Computing in Developing Economies: Drivers, Effects, and Policy Measures. IEEE Computer, 43, 47-55.

[9] Tashkandi, A. and Al-Jabri, I.M. (2015) Cloud Computing Adoption by Higher Education Institutions in Saudi Arabia: An Exploratory Study. Cluster Computing, 18, 1527-1537. 
[10] Alharthi, A., Yahya, F., Walters, R.J. and Wills, G.B. (2015) An Overview of Cloud Services Adoption Challenges in Higher Education Institutions. https://pdfs.semanticscholar.org/cb7d/d7c075e632b419733c4fbde2ae0144a595aa.pdf

[11] Haag, S. and Eckhardt, A. (2014) Organizational Cloud Service Adoption: A Scientometric and Content-Based Literature Analysis. Journal of Business Economics, 84, 407-440. https://doi.org/10.1007/s11573-014-0716-6

[12] Mell, P. and Grance, T. (2011) The NIST Definition of Cloud Computing. National Institute of Standards and Technology, Gaithersburg. https://nvlpubs.nist.gov/nistpubs/legacy/sp/nistspecialpublication800-145.pdf

[13] Mokhtar, S.A., Al-Sharafi, A., Ali, S.H.S. and Al-Othmani, A.Z. (2016) Identifying the Determinants of Cloud Computing Adoption in Higher Education Institutions. IEEE International Conference on Information and Communication Technology (ICICTM), Kuala Lumpur, 16-17 May 2016.

[14] Rivera, J. (2014) Gartner Identifies the Top 10 Strategic Technology Trends for 2014. https://www.gartner.com/newsroom/id/2603623

[15] Borgman, H.P., Bahli, B., Heier, H. and Schewski, F. (2013) Cloudrise: Exploring Cloud Computing Adoption and Governance with the TOE Framework. 46th Hawaii International Conference on System Sciences (HICSS), Wailea, Maui, HI, 7-10 January 2013.

[16] Youssef, A.E. and Alageel, M. (2012) A Framework for Secure Cloud Computing. IJCSI International Journal of Computer Science Issues, 9, 487-500.

[17] Eviwiekpaefe, A.E. and Ajakaiye, F. (2014) The Trend and Challenges of Cloud Computing: A Literature Review. International Letters of Social and Humanistic Sciences, 1, 13-20.

[18] Ahronovitz, M., et al. (2010) Cloud Computing Use Cases White Paper. Cloud Computing Use Case Discussion Group.

[19] Mell, P. and Grance, T. (2009) The NIST Definition of Cloud Computing. National Institute of Standards and Technology, 53, 50.

[20] Nandgaonkar, S.V. and Raut, A.B. (2014) A Comprehensive Study on Cloud Computing. IJCSMC, 3, 733-738.

[21] Kalpeyeva, Z.B. and Mustafina, A.K. (2013) IT-Infrastructure of University Based on Cloud Computing. IJCSI International Journal of Computer Science Issues, 10, 176-179.

[22] Mircea, M., Ghilic-Micu, B. and Stoica, M. (2011) Combining Business Intelligence with Cloud Computing to Delivery Agility in Actual Economy. Journal of Economic Computation and Economic Cybernetics Studies, 45, 39-54.

[23] Mircea, M. and Andreescu, A.I. (2011) Using Cloud Computing in Higher Education: A Strategy to Improve Agility in the Current Financial Crisis. IBIMA Publishing, 1-15. https://doi.org/10.5171/2011.875547

[24] Shayan, J., et al. (2014) Identifying Benefits and Risks Associated with Utilizing Cloud Computing. International Journal of Soft Computing and Software Engineering, 3, 416-421.

[25] Willcocks, L., Venters, W. and Whitley, E. (2014) Moving to the Cloud Corporation. Palgrave Macmillan, London.

[26] Rittinghouse, J.W. and Ransome, J.F. (2009) Cloud Computing: Implementation, Management, and Security. CRC Press, Boca Raton.

https://doi.org/10.1201/9781439806814 
[27] Bigelow, S. (2010) Pros and Cons of Moving to the Cloud. Virtual Data Centre: Considering the Cloud, 21, 4-8.

[28] Hagel, J., et al. (2010) Cloud Computing: Storms on the Horizon. Deloitte Center for the Edge, 1-20.

[29] Yuvaraj, M. (2016) Determining Factors for the Adoption of Cloud Computing in Developing Countries: A Case Study of Indian Academic Libraries. The Bottom Line, 29, 259-272. https://doi.org/10.1108/BL-02-2016-0009

[30] ISACA (2009) Business Benefits with security, Governance and Assurance Perspectives. SearchSecurity.com, 1-10.

[31] Leavitt, N. (2009) Is Cloud Computing Really Ready for Prime Time? Computer, No. 1, 15-20. https://doi.org/10.1109/MC.2009.20

[32] Kelson, N. (2010) Cloud Computing Management Audit/Assurance Program. ISACA Journal, 4-13.

[33] Tariq, M.I., et al. (2017) Factors Influencing the Cloud Computing Adoption in Higher Education Institutions of Punjab, Pakistan. International Conference on Communication, Computing and Digital Systems, Islamabad, 8-9 March 2017, 179-184.

[34] Weitz, C., et al. (2010) A Balancing Act: What Cloud Computing Means for Business, and How to Capitalize on It. Deloitte, 1-9.

[35] Bauer, E. and Adams, R. (2012) Reliability and Availability of Cloud Computing. Wiley, Hoboken. https://doi.org/10.1002/9781118393994

[36] Ercan, T. (2010) Effective Use of Cloud Computing in Educational Institutions. Procedia-Social and Behavioral Sciences, 2, 938-942. https://doi.org/10.1016/j.sbspro.2010.03.130

[37] Jian, A. and Pandy, U.S. (2013) Role of Cloud Computing in Higher Education. International Journal of Advanced Research in Computer Science and Software Engineering, 3, 966-972.

[38] Okai, S., et al. (2014) Cloud Computing Adoption Model for Universities to Increase ICT Proficiency. SAGE Open, 4, 1-10. https://doi.org/10.1177/2158244014546461

[39] Akin, O.C. and Matthew, F.T. (2014) The Impact and Challenges of Cloud Computing Adoption on Public Universities in Southwestern Nigeria. International Journal of Advanced Computer Science and Applications, 5, 13-19.

[40] Alsufyani, R., Safdari, F. and Chang, V. (2015) Migration of Cloud Services and Deliveries to Higher Education. School of Computing, Creative Technologies and Engineering. Leeds Beckett University, Headingley, 1-10. https://doi.org/10.5220/0005528500860094

[41] Hesarlo, P.S. (2014) Security, Privacy and Trust Challenges in Cloud Computing and Solutions. International Journal of Computer Network and Information Security, 6, 34-40. https://doi.org/10.5815/ijcnis.2014.08.05

[42] Oredo, J.O. and Njihia, J. (2014) Challenges of Cloud Computing in Business: Towards New Organizational Competencies. International Journal of Business and Social Science, 5, 150-160.

[43] Pawar, D.B. and Devare, A. (2014) Services, Security Challenges and Security Policies in Cloud Computing. International Journal of Renewable Energy Technology, 3, 59-63. https://doi.org/10.15623/ijret.2014.0312008

[44] Rao, R.V. and Selvamani, K. (2015) Data Security Challenges and Its Solutions in Cloud Computing. Procedia Computer Science, 48, 204-209. 
https://doi.org/10.1016/j.procs.2015.04.171

[45] Raza, M.H., et al. (2015) The Slow Adoption of Cloud Computing and IT Workforce. Procedia Computer Science, 52, 1114-1119.

https://doi.org/10.1016/j.procs.2015.05.128

[46] Jawad, Z.M., Ajlan, I.K. and Abdulameer, Z.D. (2017) Cloud Computing Adoption by Higher Education Institutions of Iraq: An Empirical Study. Journal of Education College Wasit University, 1, 591-608. https://doi.org/10.31185/eduj.Vol1.Iss28.24

[47] Shakeabubakor, A.A., Sundararajan, E. and Hamdan, A.R. (2015) Cloud Computing Services and Applications to Improve Productivity of University Researchers. International Journal of Information and Electronics Engineering, 5, 153-157.

[48] Haider, A. (2014) Business Technologies in Contemporary Organizations: Adoption, Assimilation, and Institutionalization. E-Content Generic Vendor.

[49] KPMG (2011) The Cloud-Changing the Business Ecosystem. https://www.kpmg.com/IN/en/IssuesAndInsights/ThoughtLeadership/The_Cloud_ Changing_the_Business_Ecosystem.pdf

[50] Kuo, A. (2011) Opportunities and Challenges of Cloud Computing to Improve Health Care Services. Journal of Medical Internet Research, 13, 1-19. https://doi.org/10.2196/jmir.1867

[51] Mokhtar, S.A., et al. (2014) Organizational Factors in the Adoption of Cloud Computing in E-Learning. 3rd International Conference on Advanced Computer Science Applications and Technologies, Amman, 29-30 December 2014, 188-191.

[52] Sagan, P., et al. (2011) Advancing Cloud Computing: What to Do Now? http://www3.weforum.org/docs/WEF_IT_AdvancedCloudComputing_Report_2011 .pdf

[53] Graham, D., Manikas, I. and Folinas, D. (2013) E-Logistics and E-Supply Chain Management: Applications for Evolving Business. IGI Global. https://doi.org/10.4018/978-1-4666-3914-0

[54] Tan, X. and Kim, Y. (2011) Cloud Computing for Education: A Case of Using Google Docs in MBA Group Projects. International Conference on Business Computing and Global Informatization, Shanghai, 29-31 July 2011, 641-644.

[55] Alshamaila, Y., Papagiannidis, S. and Stamati, T. (2013) Cloud Computing Adoption in Greece.

[56] Low, C., Chen, Y. and Wu, M. (2011) Understanding the Determinants of Cloud Computing Adoption. Industrial Management \& Data Systems, 111, 1006-1023. https://doi.org/10.1108/02635571111161262

[57] Taweel, A. (2012) Examining the Relationship between Technological, Organizational, and Environmental Factors and Cloud Computing Adoption. ProQuest, UMI Dissertations Publishing.

[58] Avande (2011) Global Survey: Has Cloud Computing Matured? http://www.avanade.com/ /media/documents/research\%20and\%20insights/fy11_cl oud_exec_summary.pdf

[59] Srinivasan, S. (2014) Security, Trust, and Regulatory Aspects of Cloud Computing in Business Environments. IGI Global. https://doi.org/10.4018/978-1-4666-5788-5

[60] Ross, V.W. (2010) Factors Influencing the Adoption of Cloud Computing by Decision Making Managers. ERIC.

[61] Guest, G., MacQueen, K.M. and Namey, E.E. (2011) Applied Thematic Analysis. SAGE Publications, Thousand Oaks. 
[62] Miles, M.B., Huberman, A.M. and Saldana, J. (2013) Qualitative Data Analysis: A Methods Sourcebook. SAGE Publications, Thousand Oaks.

[63] Rogers, E.M. (2010) Diffusion of Innovations. 4th Edition, Free Press, New York.

[64] Ali, M.B., Wood-Harper, T. and Mohamad, M. (2018) Benefits and Challenges of Cloud Computing Adoption and Usage in Higher Education: A Systematic Literature Review. International Journal of Enterprise Information Systems (IJEIS), 14, 64-77. https://doi.org/10.4018/IJEIS.2018100105 